4-2-2002

\title{
A Model Study of Displacement Instabilities during Cyclic Oxidation
}

Anette M. Karlsson

Cleveland State University, a.karlsson@csuohio.edu

C. G. Levi

University of California - Santa Barbara

A. G. Evans

Princeton University

Follow this and additional works at: https://engagedscholarship.csuohio.edu/enme_facpub

Part of the Mechanical Engineering Commons

How does access to this work benefit you? Let us know!

Publisher's Statement

NOTICE: this is the author's version of a work that was accepted for publication in Acta

Materialia. Changes resulting from the publishing process, such as peer review, editing, corrections, structural formatting, and other quality control mechanisms may not be reflected in this document. Changes may have been made to this work since it was submitted for publication. A definitive version was subsequently published in Acta Materialia, 50, 6, April 2, 2002; 10.1016/S1359-6454(01)00403-7

\section{Original Citation}

Karlsson, A. M., Levi, C. G., and Evans, A. G., 2002, "A Model Study of Displacement Instabilities during Cyclic Oxidation," Acta Materialia, 50(6) pp. 1263-1273.

This Article is brought to you for free and open access by the Mechanical Engineering Department at EngagedScholarship@CSU. It has been accepted for inclusion in Mechanical Engineering Faculty Publications by an authorized administrator of EngagedScholarship@CSU. For more information, please contact library.es@csuohio.edu. 


\title{
A model study of displacement instabilities during cyclic oxidation
}

\author{
A.M. Karlsson ${ }^{\text {a, }}{ }^{*}$, C.G. Levi ${ }^{\text {b }}$, A.G. Evans ${ }^{\text {a }}$ \\ a Princeton Materials Institute, Princeton University, Browen Hall, 70 Prospect Avenue, Princeton NJ 08540-5211, USA \\ ' Materials Department, UCSB, Santa Barbara CA 91360, USA
}

\section{Introduction}

Shape distortions occur in certain $\alpha-\mathrm{Al}_{2} \mathrm{O}_{3}$ forming alloys subject to cyclic oxidation [1-8]. The most vivid manifestation is the development of periodic downward displacements in a thermal barrier system with a Pt-aluminide bond coat $(\beta-\mathrm{NiAl}$ with Pt in solution) [4]. The effect has been related to cyclic plastic strains in the bond coat [1-7], motivated by the thermal expansion misfit between the thermally grown oxide (TGO) and the substrate, combined with the growth strains in the TGO. The

\footnotetext{
* Corresponding author.

E-mail address: karlsson@princeton.edu (A.M. Karlsson).
}

present article attempts to broaden basic understanding of this phenomenon through a model study involving a combination of simulations and observations made on a FeCrAlY material that oxidizes to form $\alpha-\mathrm{Al}_{2} \mathrm{O}_{3}$.

Three factors appear to have a strong influence on the displacements [7-9].

(i) The growth strain when the bond coat forms $\alpha-\mathrm{Al}_{2} \mathrm{O}_{3}$ [7] expresses the overall volume increase when the alloy is converted into oxide. It has two components: a thickening strain normal to the surface, and a lengthening strain parallel with the surface. While the underlying mechanisms governing the partitioning of the 


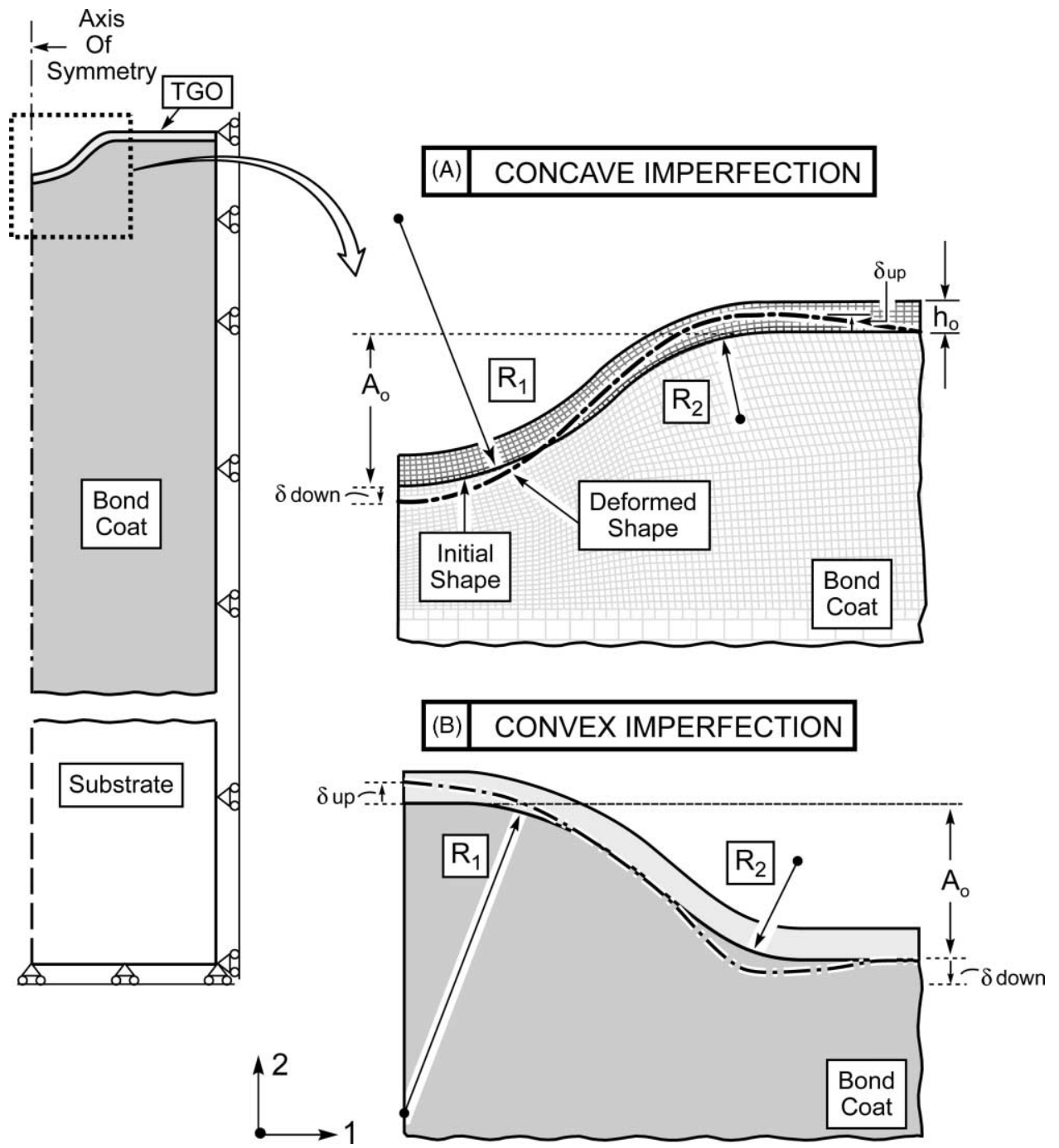

Fig. 1. The imperfection morphologies addressed in the analysis (A) concave, including an example of a finite element mesh and (B) convex.

strain into these components is not completely understood, it is appreciated that the lengthening strain is induced by new $\mathrm{Al}_{2} \mathrm{O}_{3}$ forming internally on the vertical grain boundaries [7-9]. It is also believed that this strain component has a larger influence on the instability than the thickening [10].

(ii) The shape of the imperfection is thought to have an important influence, parti- cularly its aspect ratio and curvature $[1,2,4]$.

(iii) The displacement rate appears to be strongly dependent on the frequency of thermal cycling $[1,4,10,11]$. Namely, the higher the frequency, the more rapid the displacement. In the isothermal limit, the rate is negligibly small.

This article addresses the sensitivity of the dis- 
placements to these phenomena, by designing an experiment to probe the major effects and then performing simulations to superpose on the experiments. The model experiments involve a FeCrAlY material with controlled imperfections [12]. Changes in the shape of imperfection are characterized subject to cyclic and isothermal oxidation, for comparable TGO growth.

Based on the ensuing insights, an attempt is made to clarify the role of the surface treatment imparted to the bond coat layer [6,11]. In commercial practice, this treatment comprises a grit blasting process that leaves impressions in the surface, represented by undulations (Fig. 1(A)). In the asprocessed state, absent a grit-blasting step, the surface contains ridges (protrusions) located above the grain boundaries in the bond coat [6,11] (Fig. 1(B)). The simulation protocol is used to compare and contrast these two imperfection categories and the simulated response is related to recent observations [11].

\section{(A)}

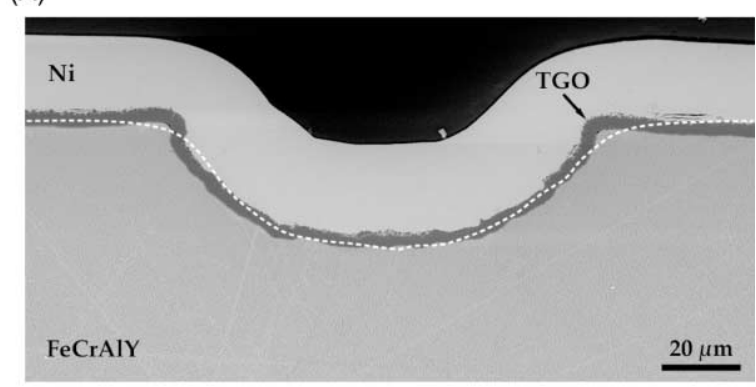

(B)

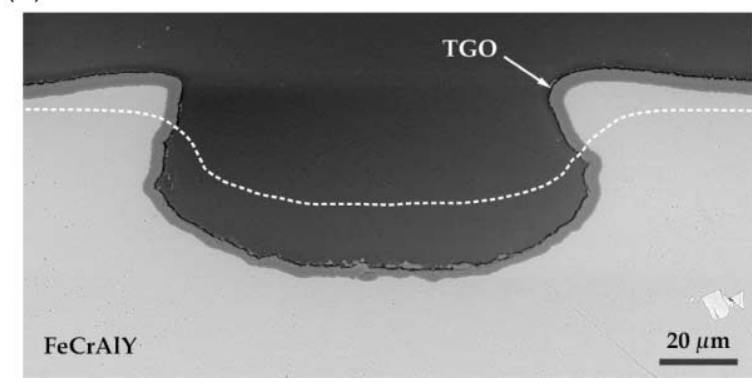

Fig. 2. Cross-sections of the FeCrAlY foils used in the experiment, showing the groove profile before (white dashed line) and after oxidation. (A) After isothermal exposure at $1150^{\circ} \mathrm{C}$ for 24 h. (B) After 24 cycles at the same maximum temperature, with $1 \mathrm{~h}$ dwell time each. (Courtesy of N. Rebollo.)

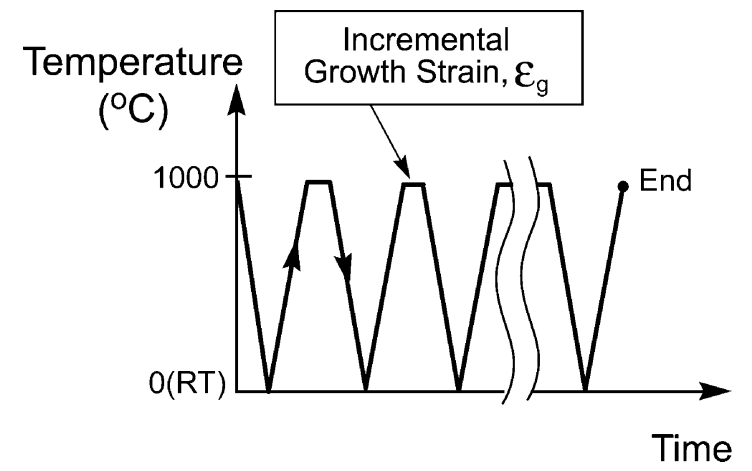

Fig. 3. The load sequence used in the numerical model.

\section{Observations}

Foils of FeCrAlY about $1 \mathrm{~mm}$ thick were annealed at $1100^{\circ} \mathrm{C}$ for $17 \mathrm{~h}$ in a purified inert gas environment. They were subsequently cut into squares, $25 \mathrm{~mm}$ on the side, and polished to an optical quality finish. A series of grooves about 20 $\mu \mathrm{m}$ deep, $100 \mu \mathrm{m}$ wide, and 1.25 or $2.5 \mathrm{~mm}$ apart, were then cut into the surface using a dicing saw and a precision diamond blade. The surface was planarized by carefully re-polishing, lightly etched and ultrasonically cleaned. Groove profiles at different locations, identified by fiducial marks, were characterized by profilometry.

One specimen prepared in the above manner was subjected to isothermal oxidation in air at $1150^{\circ} \mathrm{C}$ for $24 \mathrm{~h}$. A second, nominally identical, specimen was subjected to 24 oxidation cycles in air. Each oxidation cycle comprised a $10 \mathrm{~min}$ ramp up to $1150^{\circ} \mathrm{C}$, a $1 \mathrm{~h}$ dwell at this temperature, a $10 \mathrm{~min}$ ramp down to ambient and a 10 min hold at ambient. (Slight bending of the thermally cycled specimen was observed, with the grooved side becoming concave [11]). After the prescribed oxidation treatments, the specimens were cut along the sections defined by the fiducial marks, polished and examined by scanning electron microscopy.

Representative cross-sections of the grooves in each specimen are shown in Fig. 2. The change in the groove profile after 24 cycles (Fig. 2(B)) vividly demonstrates "pile-up" of the alloy at the periphery of the groove. The thermally grown $\alpha$ $\mathrm{Al}_{2} \mathrm{O}_{3}$ has a relatively uniform thickness $(\sim 2 \mu \mathrm{m})$ at all locations outside and within the groove, 
albeit somewhat rougher and with more variation at the bottom of the latter. The original profile measured at this location is superposed on the micrograph in Fig. 2(B), revealing substantial deformation. By comparison, the cross-section of a similar groove in the isothermally exposed sample shows much less distortion of the groove edges, and only minor deformation of the overall shape. The oxide thickness is essentially the same in both cases, reflecting the similar cumulative time at the maximum temperature.

Comparison of the profiles taken before and after thermal cycling reveals three distinctive features. (a) Material pile-up occurs at the edges, with an upward displacement of $\sim 7 \mu \mathrm{m}$. (b) The material at the base of the groove displaces downward by $\sim 17 \mu \mathrm{m}$ (for an initial groove depth of $\sim 23 \mu \mathrm{m}$ ). (c) The groove becomes narrower at the periphery and wider at the bottom.
In the following sections, various simulations are performed with the goal of establishing the TGO growth characteristics that govern these shape changes.

\section{Description of model}

The calculations are conducted by adapting a previous model [1]. The computer program ABAQUS is used, which allows simulation of large deformations of the bond coat and the TGO. The geometry comprises a $2 \mathrm{~mm}$ thick substrate (Young's modulus, $190 \mathrm{GPa}$, Poisson ratio 0.3, thermal expansion coefficient $14 \mathrm{ppm} /{ }^{\circ} \mathrm{C}$ ) and a (50 $\mu \mathrm{m}$ thick) elastic/perfectly plastic bond coat with temperature invariant yield strength, $\sigma_{y}^{\text {bc }}$, Young's modulus $E_{\mathrm{bc}}=190 \mathrm{GPa}$, Poisson ratio 0.3, thermal expansion coefficient $14 \mathrm{ppm} /{ }^{\circ} \mathrm{C}$. An axi-

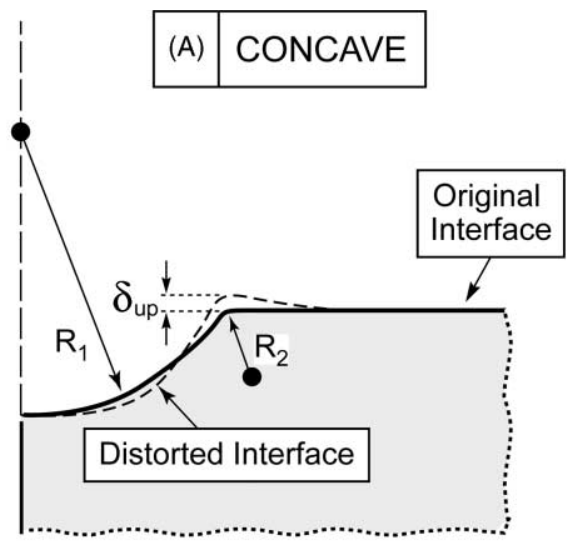

(B) CONVEX
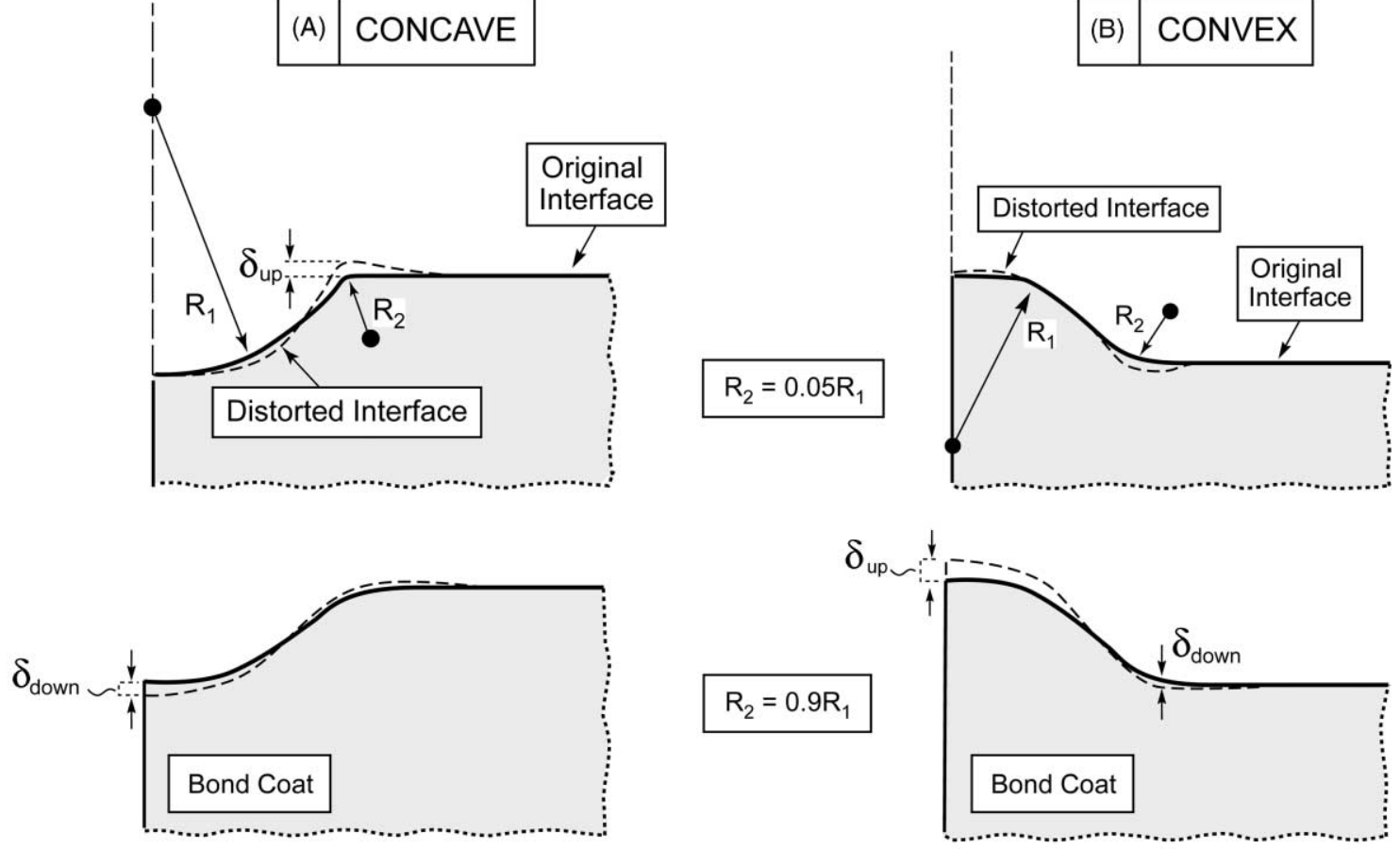

$$
\sigma_{Y}=200 \mathrm{MPa}, \mathrm{N}=24
$$

Fig. 4. The change in shape of the bond coat for $\sigma_{y}^{\text {bc }}=200 \mathrm{MPa}$ after 24 thermal cycles for (A) concave and (B) convex imperfections. 
symmetric surface imperfection is introduced (Fig. 1(A)). An initial, thin TGO (thickness $0.5 \mu \mathrm{m}$ ) is incorporated over the surface of the bond coat. The TGO has Young's modulus, $E_{\mathrm{tgo}}=380 \mathrm{GPa}$, Poisson ratio 0.2 , thermal expansion coefficient $8 \mathrm{ppm} /{ }^{\circ} \mathrm{C}$. Most calculations are performed with a representative imperfection having depth $A_{0}=2.4 \mu \mathrm{m}$, a major radius of curvature $R_{1}=5 \mu \mathrm{m}$, and a minor radius of curvature that varies in the range: $\mathfrak{R}=R_{2} / R_{1}=0.05,0.2,0.5$ and 0.9 . The objective is to follow the shape changes as this structure experi-

\section{\begin{tabular}{l|l|l|} 
(A) & $\mathrm{R}_{2} / \mathrm{R}_{1}=0.05$ & Concave \\
\hline
\end{tabular}}
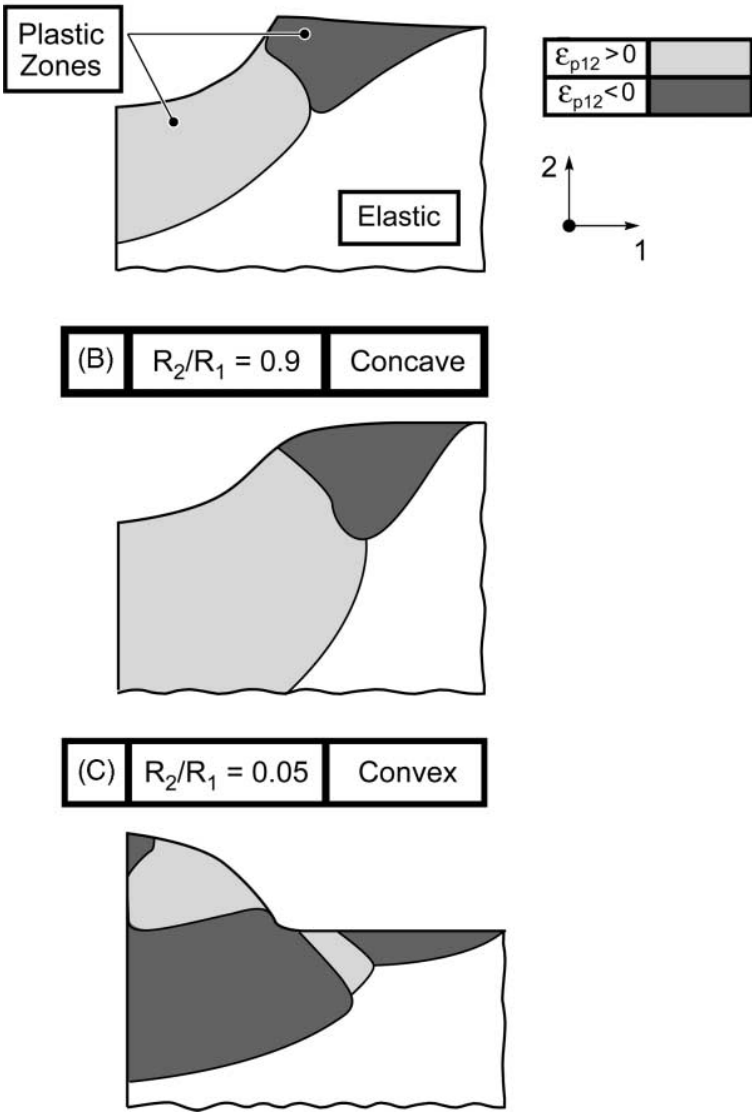

Fig. 5. The accumulated plastic shear strain after 24 cycles indicates different zones of plastic yielding as the source for the "up" and "down" displacement of the bond coat. (A) Concave imperfection $R_{2} / R_{1}=0.05$; (B) concave imperfection $R_{2} / R_{1}=0.9$ $\left(\sigma_{y}^{\mathrm{bc}}=200 \mathrm{MPa}\right)$; and $(\mathrm{C})$ convex imperfection $R_{2} / R_{1}=0.05$. $\left(\sigma_{y}^{\mathrm{bc}}=200 \mathrm{MPa}\right)$. ences thermal cycling and as the oxide layer grows. A second imperfection category is briefly addressed, by performing a few calculations for protruding imperfections (Fig. 1(B)), with corresponding dimensions.

To realize numerical tractability, yet without suppressing important physical effects, three simplifications are used [1].

(i) Much complexity is averted by allowing the bond coat to be elastic/perfectly plastic with temperature independent properties. Temperature dependent yielding

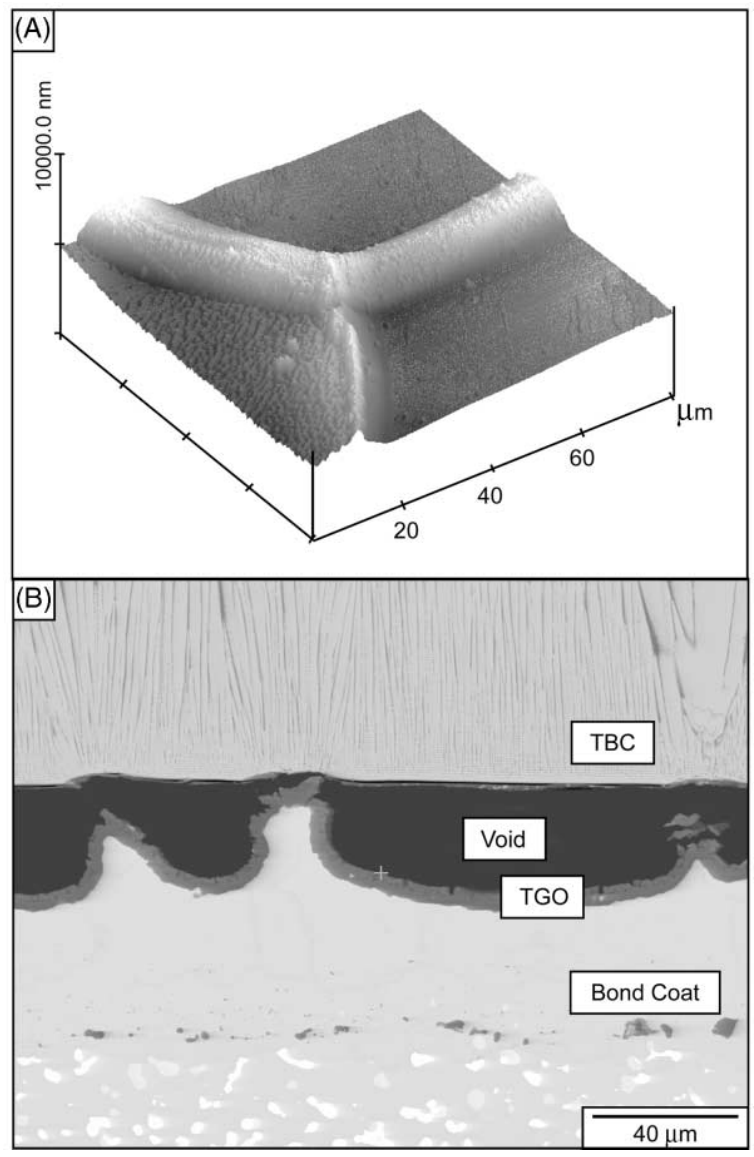

Fig. 6. (A) The as-process state of the bond coat contains ridges above the bond coat. (B) Protruded areas after thermal cycling. In this case, a void has developed between the TGO and the TBC due to interfacial cracking. (Courtesy D.R. Mumm and I. Spitsberg, [11].) 
changes the details, but not the overall trends [1].

(ii) It is essential to allow stress relaxation in the TGO at the peak temperature $[1,10]$. Otherwise, unrealistically large stresses develop and, moreover, the difference between the cyclic and isothermal responses vanishes [10]. This effect is simulated by yielding the TGO at the peak temperature. At all other temperatures, the TGO is considered to be elastic. For consistency with experimental stress measurements [8,13], yielding is assumed to occur when the Mises stress reaches, $\sigma_{y}^{\mathrm{tgo}}=1 \mathrm{GPa} .{ }^{1}$ This property is a parameter in the simulations.

(iii) The substrate does not yield and is taken

\section{GENERALIZED PLANE STRAIN}

\section{(A) $R_{2} / R_{1}=0.05$}
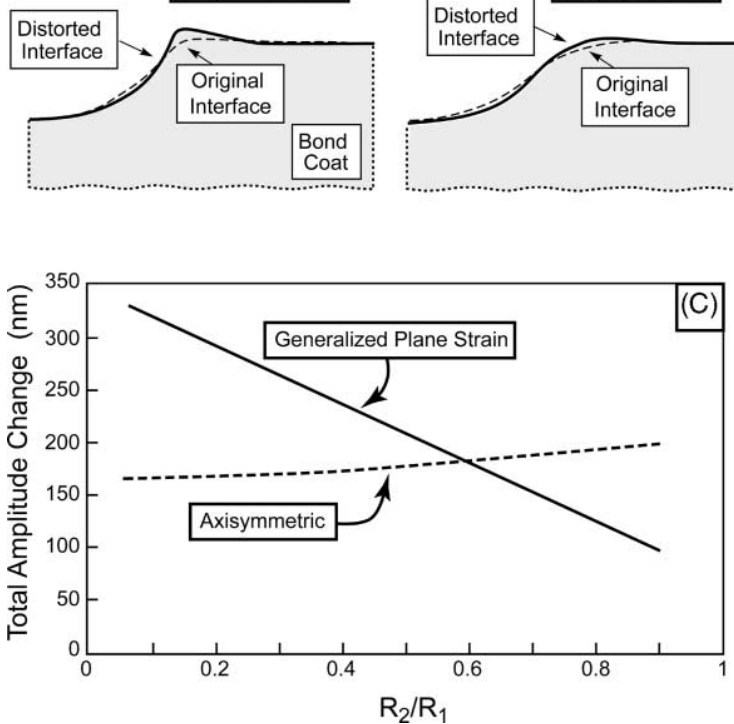

Fig. 7. The change in shape of the bond coat for generalized plane strain: (A) $R_{2} / R_{1}=0.05$; (B) $R_{2} / R_{1}=0.9$; (C) compared to axisymmetric case. $\left(\sigma_{y}^{\mathrm{bc}}=200 \mathrm{MPa}, 24\right.$ thermal cycles $)$.

${ }^{1}$ This is done by letting $\sigma_{y}^{\mathrm{tgo}}=10 \mathrm{GPa}$ for $T<900^{\circ} \mathrm{C}, \sigma_{y}^{\mathrm{tgo}}=1$ GPa for $T>1000^{\circ} \mathrm{C}$, and letting $\sigma_{y}^{\text {tgo }}$ vary linearly in between.

\section{GENERALIZED PLANE STRAIN}

\section{(A) Periodic Boundaries}

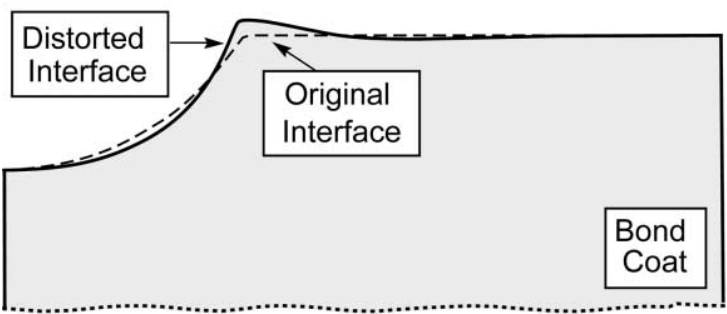

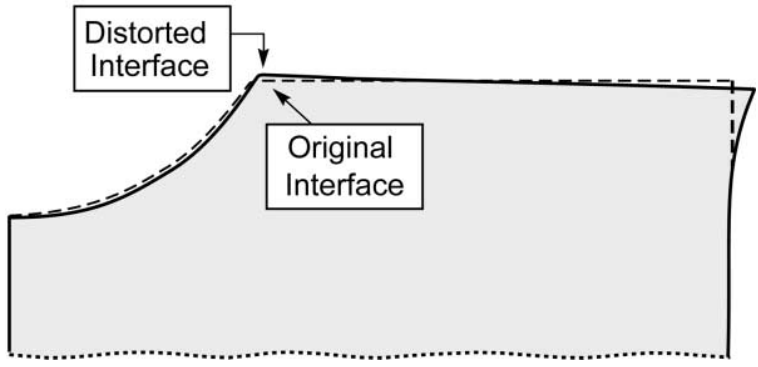

Fig. 8. Deformation of the bond coat for generalized plane strain comparing (A) Periodic Boundaries with (B) Free Boundaries. ( $\sigma_{y}^{\mathrm{bc}}=200 \mathrm{MPa}, 24$ thermal cycles).

to be linear elastic. The thermal expansion misfit with the bond coat is neglected [1].

The growth conditions used in the simulations, while described elsewhere [1], are elaborated here because of their criticality to the effects found in the simulations and observed in the experiments. The TGO growth is simulated by a stress-free strain tensor applied at the maximum temperature in the TGO [1]. The total strain, $\varepsilon_{\text {tot }}$, has four components: $\varepsilon_{\text {tot }}=\varepsilon_{\mathrm{E}}+\varepsilon_{\mathrm{P}}+\varepsilon_{\theta}+\varepsilon_{\mathrm{G}}$ (where $\varepsilon_{\mathrm{E}}$ is the elastic strain, $\varepsilon_{\mathrm{P}}$ the inelastic strain, $\varepsilon_{\theta}$ is the thermal strain, and $\varepsilon_{\mathrm{G}}$ is the strain caused by the 
oxide growth). The strain caused by the oxide growth has two components, $\varepsilon_{\mathrm{G}}=\varepsilon_{t} \mathbf{e}^{\perp}+\varepsilon_{G} \mathbf{e}^{\|}$ (where $\mathbf{e}^{\perp}$ is perpendicular and $\mathbf{e}^{\| l}$ is parallel to the $\mathrm{TGO} /$ bond coat interface). The strain $\varepsilon_{\mathrm{g}}$ is related to the Pilling-Bedworth ratio $[9,13]$. Note that $\varepsilon_{\mathrm{G}}$ and $\varepsilon_{\theta}$ are both stress free strains. The growth strain, $\varepsilon_{\mathrm{G}}$, is applied at the high temperature (Fig. 3 ) by using the ABAQUS subroutine UEXPAN. It is treated as a variable. For initial purposes, to be consistent with prior analysis $[1,2]$, the simulations are performed with initial TGO thickness $h_{0}=0.5$ $\mu \mathrm{m}$, and a thickening strain per cycle, $\varepsilon_{\mathrm{t}}=10^{-2}$. For these choices, the nominal increase in thickness over 24 cycles is $\Delta h=0.12 \mu \mathrm{m}$ (note that despite fixed growth strains, the constraint on the TGO and

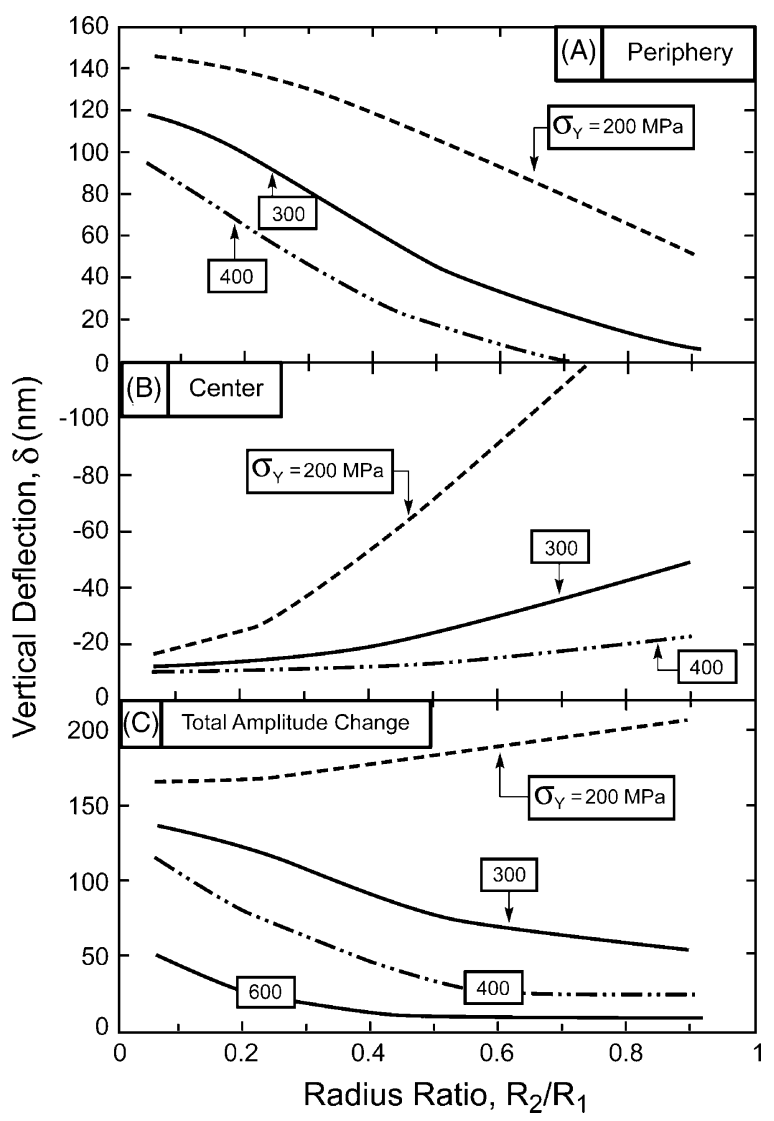

Fig. 9. A summary of shape changes for a concave imperfection after 24 thermal cycles: (A) "up" displacement at the periphery of the imperfection; (B) "down" displacement at the center of the imperfection; (C) total amplitude change. $\left(\sigma_{y}^{\mathrm{bc}}=200 \mathrm{MPa}\right)$.
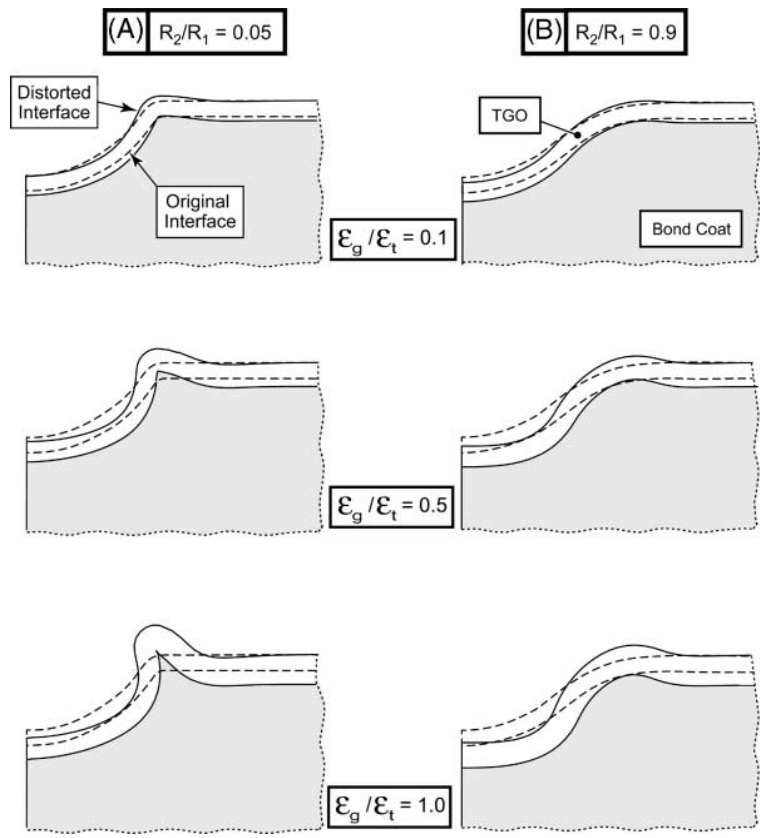

Fig. 10. The change in shape of the bond coat and TGO for various ratios of the lengthening to thickening components of the growth strain (A) $R_{2} / R_{1}=0.05$; (B) $R_{2} / R_{1}=0.9$. ( $\sigma_{y}^{\mathrm{bc}}=200 \mathrm{MPa}$, 24 thermal cycles, axisymmetric conditions).

the associated yielding cause local thickness variations). Larger $\Delta h / h_{0}$ are not used since the instability is primarily affected by the in-plane component of the growth strain [10].

\section{Simulations}

\subsection{Displacements and strains}

\subsubsection{General trends}

Trends are demonstrated by conducting cyclic and isothermal simulations with a bond coat yield strength, $\sigma_{y}^{\mathrm{bc}}=200 \mathrm{MPa}$ and a growth strain, $\varepsilon_{\mathrm{g}}=$ $10^{-3}$ [4]. The effects of the radius ratio $\Re$ on the cyclic deformations are illustrated in Fig. 4(A). Most notable are the substantial upward displacements around the periphery of the imperfection, that increase in relative extent as the minor radius of curvature $\Re$ decreases. Such displacements are in accordance with those found experimentally. The downward displacement of the base, also found experimentally, only becomes prominent 


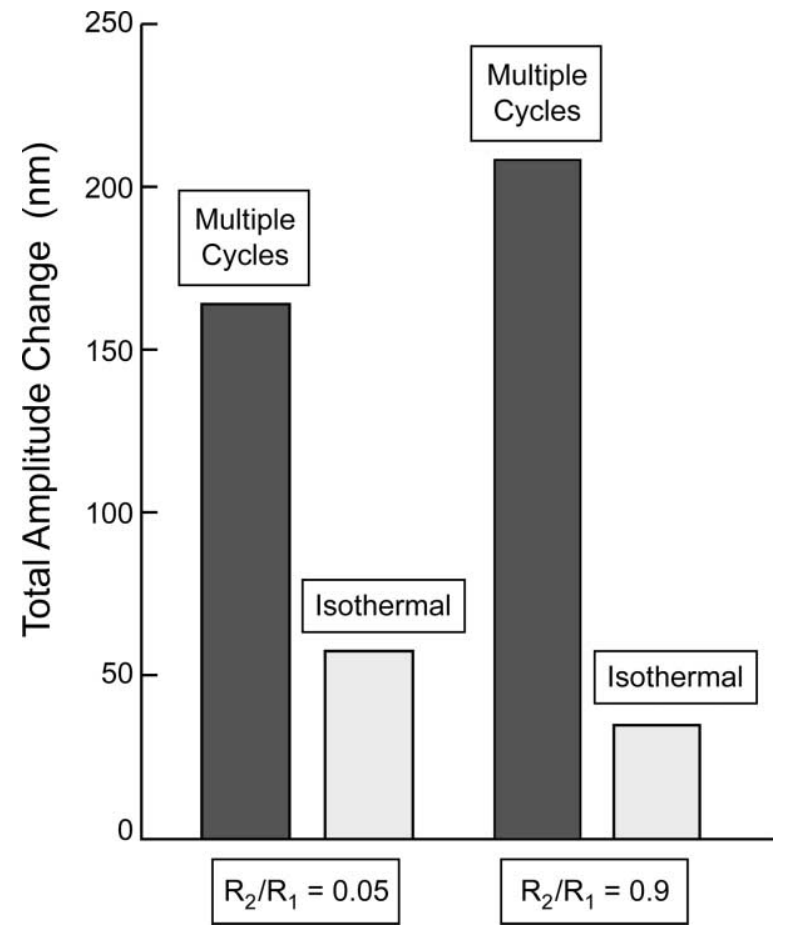

Fig. 11. The same amount of growth strain is applied during isothermal conditions compared to cyclic conditions. The amplitude change of the imperfection is significantly smaller for cyclic condition. ( $\sigma_{y}^{\mathrm{bc}}=200 \mathrm{MPa}, 24$ thermal cycles).

when $\Re$ approaches unity. Note that in all cases the displacements conserve the volume of the bond coat, as required by plasticity.

The contours of the cumulative plastic shear strain $\left(\varepsilon_{\mathrm{p} 12}\right)$ indicate that there are two plastic zones (Fig. 5): one centered near the imperfection periphery, around $R_{2}$, and the other around the axis of symmetry, based on $R_{1}$. These develop because each curved section induces concentrated deviatoric strains of opposite sign. When the minor radius of curvature, $R_{2}$, is small, the zone centered at the surface dominates. The plastic displacements focus toward the periphery, resulting in large plastic strains with associated upward displacement. Conversely, as $\Re \rightarrow 1$, the plastic zone centered towards $R_{1}$ dominates. These plastic strains rationalize the relative trends in $\delta_{\text {up }}$, and $\delta_{\text {down }}$, (Fig. 4).

A convex imperfection (Fig. 1(B) and Fig. 6(A)) exhibits inverted behavior: an upward displacement at the center and a downward displacement at the periphery (Fig. 4(B)). Such displacements are in accordance with those found experimentally (Fig. 6(B)) [11]. The contours of the cumulative plastic shear strain, $\varepsilon_{\mathrm{p} 12}$, (Fig. 5) display a more complex plastic straining scenario. Four zones are present with two dominant zones centered near the imperfection periphery, around $R_{2}$, and the others across the protrusion. Further investigations of the evolution of protruding imperfections are conducted in a separate study [14].

\subsubsection{Sensitivity study}

In order to realize displacement responses corresponding to those found experimentally, the influence of the following phenomena have been investigated: (i) the difference between axi-symmetric and plane-strain configurations, (ii) the ratio of inplane to thickening strains in the TGO, (iii) the transverse boundary conditions, (iv) the bond coat yield strength. The most important are evident from pictorial views, displayed on Figs 7-11. A comparison between axi-symmetry and plane strain (Fig. 7) illustrates that the upward deflection at the periphery and the downward displacement at the center are generally larger for axi-symmetry, except for the highest $\mathfrak{R}$. Changing the lateral boundary condition from periodic to stress-free (Fig. 8) results in a smaller amplitude change, as well as a distortion at the external boundary. However, the changes in shape at the imperfection are small relative to those found experimentally. Increasing the bond coat yield strength (Fig. 9) diminishes the displacements. [Note that even at the highest yield strength, some upward displacement occurs at small $\mathfrak{i}]$.

Increasing the growth strain, $\varepsilon_{\mathrm{g}} / \varepsilon_{\mathrm{t}}$ (Fig. 10) causes the convolutions at the imperfection periphery to increase dramatically. In particular, both upward and inward displacements arise as $\varepsilon_{\mathrm{g}} / \varepsilon_{\mathrm{t}}$ increases, accompanied by greater lengthening of the TGO, with associated distortions of the alloy. The results determined at the largest $\varepsilon_{\mathrm{g}} / \varepsilon_{\mathrm{t}}$ particularly when $\Re$ is also small and the bond coat yield strength low $\left(\sigma_{y}^{\mathrm{bc}}=200 \mathrm{MPa}\right)$, exhibit displacements closest to those determined experimentally. While the level of correspondence appears satisfactory, note that the simulations still underestimate the downward displacements and do not 
reproduce the narrowing of the groove. To achieve complete correspondence a larger sensitivity study would be needed with $\sigma_{y}^{\text {tgo }}$ as a variable, incorporating a more explicit yielding representation for the alloy.

Corresponding calculations performed for the same TGO growth, subject to single cycle (isothermal) conditions (Fig. 11), indicate that the displacements are minimal, again consistent with the experiments.

\subsection{Stresses in the $T G O$}

The stresses induced in the TGO are of interest for assessments of $\mathrm{TBC}$ failure [7]. The stresses tangential to the $\mathrm{TBC} /$ bond coat interface are displayed in Fig. 12. At ambient, the tensile stresses relevant to brittle cracking occur primarily at the periphery of concave imperfections having the smallest $\Re$ (Fig. 12(A, B)), where the stretching strain induced by deformation of the bond coat is greatest. At all other locations, as well as for all other $\Re$, the stresses are compressive. The average compressive stress ranges from 2.4 to $3.0 \mathrm{GPa}$ for $\Re=0.05$ and 0.9 , respectively. At elevated temperature, in all cases, tangential tensile stresses occur locally (Fig. 12(C, D)), both at the periphery and at the sides of the undulation, with implications for through-thickness rupture. These stresses are associated with bending of the TGO.

The stresses perpendicular to the $\mathrm{TGO} /$ bond coat interface are much smaller and less sensitive to $\Re$. Local interface tensions occur at ambient, primarily around the periphery for the concave imperfection (Fig. 13(A)) and near the apex for the convex imperfection (Fig. 13(B)). These stresses have implications for decohesion of the $\mathrm{TGO} /$ bond coat interface [7].

\subsection{TGO thickness}

Inspection of Fig. 10 indicates that the TGO thickness becomes larger and less uniform as the lengthening strain increases (recall that the thick-
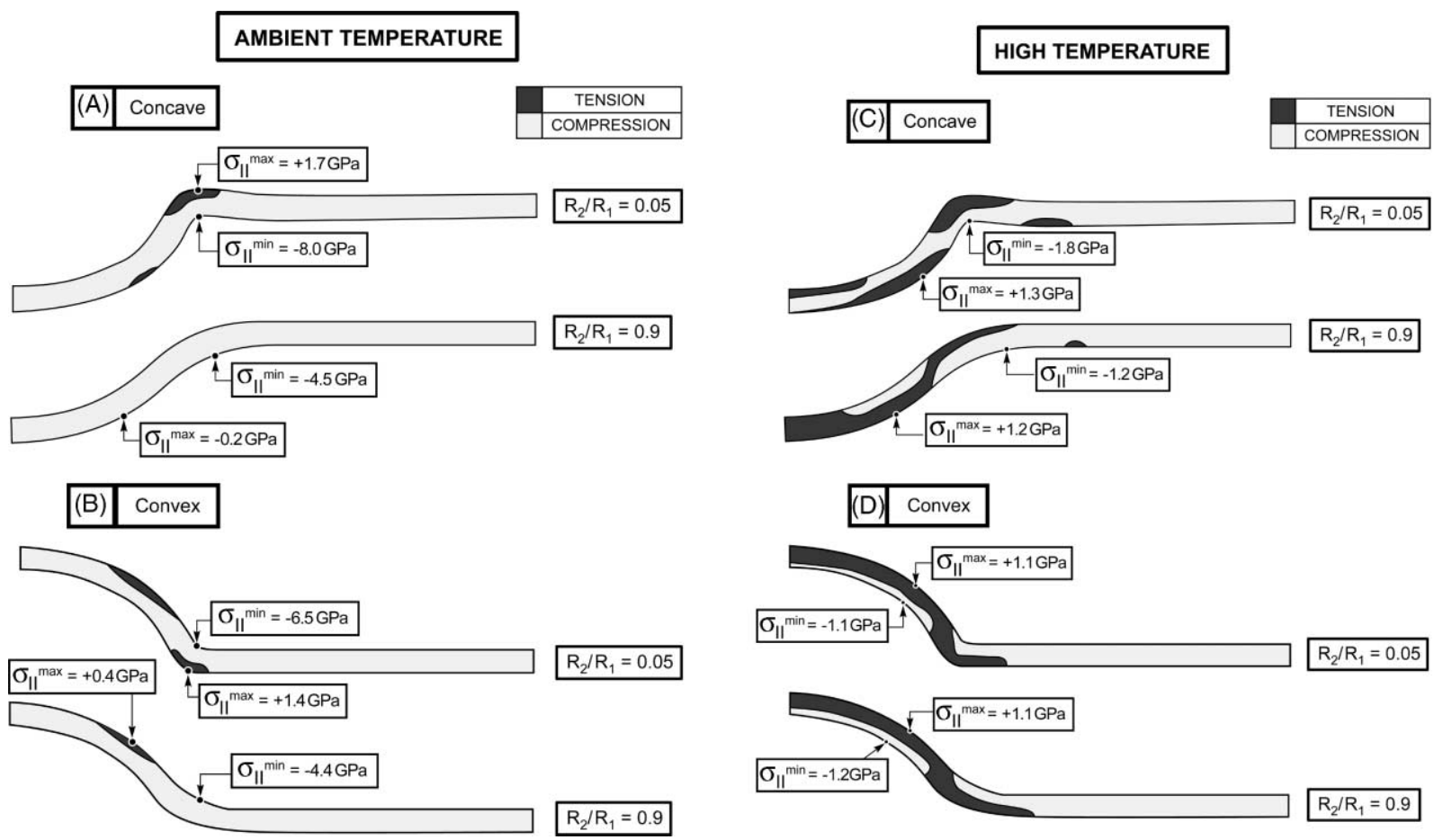

Fig. 12. Stresses in the TGO tangential to the BC/TGO interface: ambient temperature for (A) concave and (B) convex imperfections: at elevated temperature for $(C)$ concave and (D) convex imperfections. ( $\sigma_{y}^{\mathrm{bc}}=200 \mathrm{MPa}, 24$ thermal cycles). 


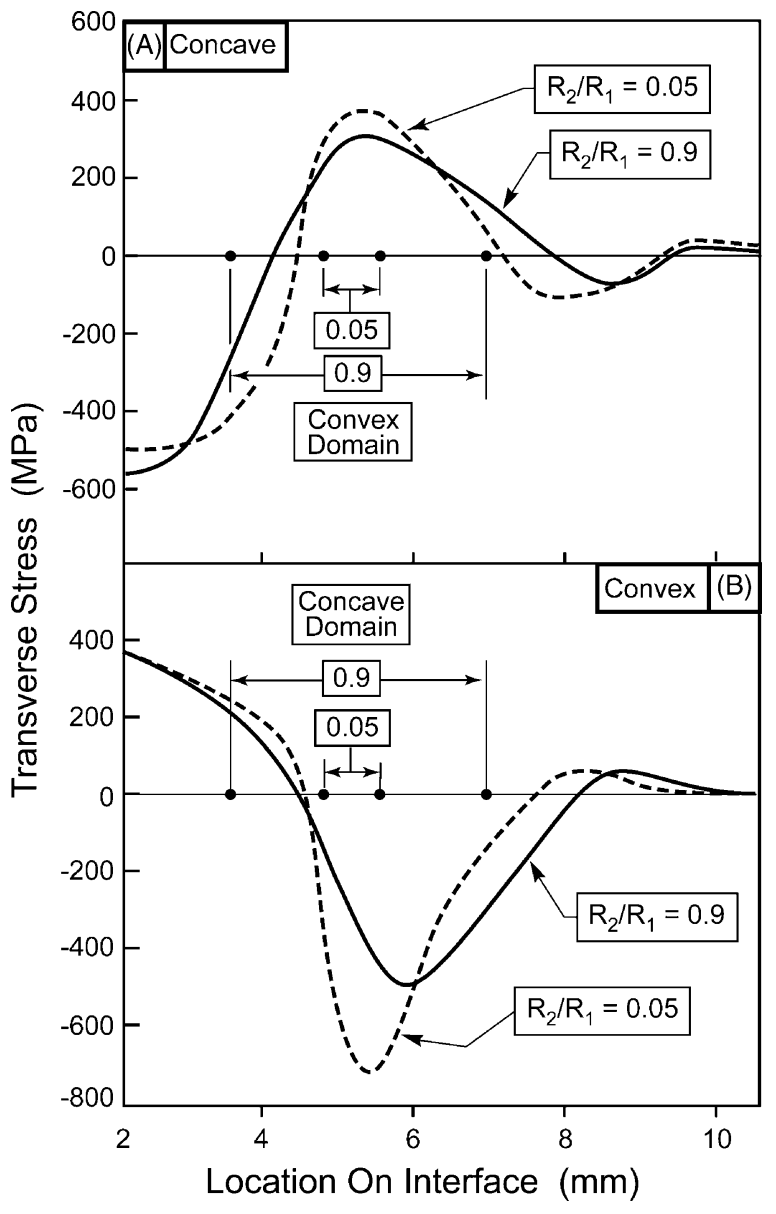

Fig. 13. Stresses in the TGO transverse to the bond coat/TGO interface, as a function of its location of the interface (measured from the center of the imperfection) for (A) Concave and (B) Convex imperfections ( $\sigma_{y}^{\mathrm{bc}}=200 \mathrm{MPa}, 24$ thermal cycles $)$.

ening growth strain has been kept constant). The trends are plotted in Fig. 14. The larger $\varepsilon_{\mathrm{g}} / \varepsilon_{\mathrm{t}}$ causes more of the alloy to be converted into oxide during each cycle. However, despite adding the extra TGO to the internal grain boundaries, through a lengthening strain, it is manifest as an increase in a thickening strain on the planar segments (Fig. 14). This happens because the induced in-plane compression exceeds the yield strength of the TGO, resulting in mass redistribution by plastic flow, with an increase in the thickening as $\varepsilon_{\mathrm{g}} / \varepsilon_{\mathrm{t}}$, increases (consistent with a plastic Poisson ratio, $\left.v_{\mathrm{p}}=0.5\right)$. The response within the imperfection differs. The compressions and local tensions (Fig. 12)

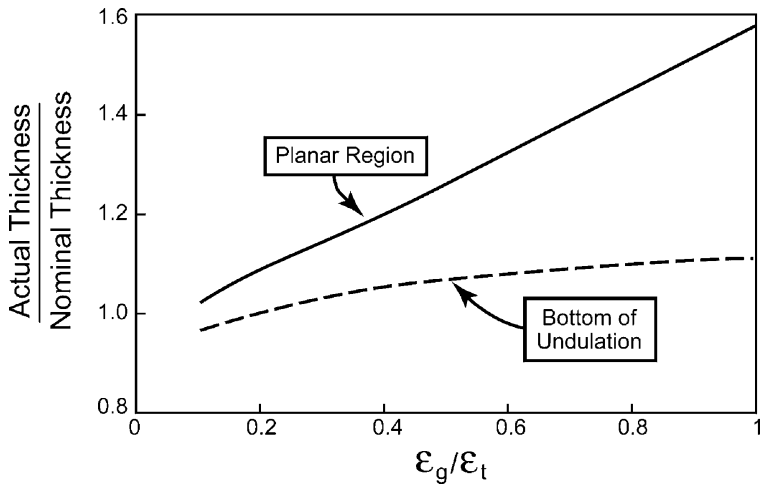

Fig. 14. Normalized TGO thickness as a function of $\varepsilon_{\mathrm{g}} / \varepsilon_{\mathrm{t}}$ showing an increase in a thickening in the planar segments, despite adding the extra TGO to the internal grain boundaries. $\left(\sigma_{y}^{\mathrm{bc}}=200 \mathrm{MPa}, 24\right.$ thermal cycles.)

allow thickening in some locations and thinning in others.

These variations in TGO thickness, combined with the high sensitivity of the distortions to the growth characteristics, suggest that experiments performed on tailored imperfections, when combined with complete simulations, might be capable of providing fundamental understanding about TGO formation. That is, detailed measurements of TGO thickness and of shape changes could be used to evaluate $\varepsilon_{\mathrm{g}} / \varepsilon_{\mathrm{t}}$ for a range of oxidation conditions.

\section{Conclusion}

Simulations and experiments have verified that alloys susceptible to $\alpha-\mathrm{Al}_{2} \mathrm{O}_{3}$ formation experience surface shape changes upon cyclic oxidation. These changes occur at imperfections in the surface. They are motivated by misfit strains caused by the thermal expansion differential between $\alpha$ $\mathrm{Al}_{2} \mathrm{O}_{3}$ and the alloy upon cooling, in combination with strains associated with oxide growth at the highest temperature in the cycle. The displacements allowed by cyclic plastic deformation of the alloy can be inhibited by using an alloy with sufficiently high yield strength.

The shape changes are dependent on the imperfection profile, characterized by the ratio, $\Re$, of the radius of curvature at the perimeter to that at the 
center of symmetry, as well as the incidence of thermal cycling. Most vividly, upon cycling, imperfections with small $\Re$ exhibit pile-up at the perimeter, with corresponding downward displacements at the axis of symmetry, resulting in an overall increase in imperfection amplitude. Such distortions do not occur upon isothermal oxidation. Inverted shape changes are predicted for convex imperfections.

A sensitivity study that compares the measured and simulated shape changes has demonstrated that the effects are most strongly dependent on the ratio of the lengthening-to-thickening component of the TGO growth strain, with a relatively large lengthening component needed to achieve closest correspondence with experimental observations. A soft bond coat is also required, as well as a TGO that yields at the growth temperature. The parameters used for the simulations underestimate the displacements found experimentally. Establishing complete correspondence will require additional understanding of TGO growth, its yielding and of the stress/strain properties of FeCrAlY.

\section{References}

[1] Karlsson AM, Evans AG. Acta Materialia 2001;49:1793-804.

[2] He MY, Evans AG, Hutchinson JW. Acta Materialia 2000;48:2593-601.

[3] Mumm DR, Evans AG. Acta Materialia 2000;48:1815-27.

[4] Mumm DR, Evans AG, Spitsberg I. Acta Materialia 2001;49:2329-40.

[5] Ambrico JM, Begley MR, Jordan EH. Acta Materialia 2001;49:1577-88.

[6] Gell M, Vaidyanathan K, Barber B, Cheng J, Jordan E. Metallurgical and Materials Transactions 1999;30A:42735.

[7] Evans AG, Mumm DR, Hutchinson JW, Meier GH, Pettit FS. Progress in Materials Science 2001;46:505-53.

[8] Tolpygo V, Clarke DR. Acta Materialia 2000;48:3283-93.

[9] Rhines FN, Wolf JS. Metallurgical Transactions 1970;1:1701-5.

[10] Karlsson AM, Hutchinson JW, Evans AG. (to appear in Journal of the Mechanics and Physics of Solids).

[11] Spitsberg I, Mumm DR, Evans AG. Journal of Materials Research, submitted for publication.

[12] Rebollo N, Levi CG. (in preparation).

[13] Stiger MJ, Yanar NM, Topping MG, Pettit FS, Meier GH. Z Metallk 1999;90:1069-78.

[14] Mumm DR, Karlsson AM, Evans AG. (in preparation). 